\title{
AUTOCATALYTIC REDUCTION AND CHARACTERISTICS OF BORON-CONTAINING COATINGS
}

\author{
Victor Covaliov ${ }^{\mathrm{a}}$, Olga Covaliova ${ }^{\mathrm{a}}$, Mikhail Ivanov ${ }^{\mathrm{b}}$, Andrey Drovosekov ${ }^{\mathrm{b}}$ \\ ${ }^{a}$ Research Center of Applied and Ecological Chemistry of Moldova State University, 60 Mateevici Street, MD 2009, \\ Chisinau, Republic of Moldova \\ ${ }^{b}$ A.N.Frumkin Institute of Physical Chemistry and Electrochemistry, 31 LeninskyProsp., 119071, Moscow, Russia \\ *E-mail: covaleva.olga@yahoo.com; Phone/Fax: +37322 577556
}

\begin{abstract}
The research results of the plating conditions, chemical composition and properties of Ni-B coatings and Ni-Re-B, Ni-Mo-B and Ni-W-B alloys are given. It was shown that introduction of alloying elements (Re, Moand W) in the composition of Ni-containing coatings modifies the catalytic activity of the alloys' surface, with regard to the parallel reactions of dimethylamino-borane(DMAB) heterogeneous hydrolysis, Ni reduction and evolving of the molecular hydrogen. It was found that with the increase in concentration of alloying element, boron contents in the coatings is decreased to the trace amounts. The effect of alloys composition on hydrogen evolving overvoltage was studied. Due to the low overvoltage of hydrogen evolving (HE) on the alloy Ni-Re-B surface (11 at.\% Re), it can be used as electrode for hydrogen generation from water in the electrolytic cell with novel design and improved technical-economical indicators.
\end{abstract}

Keywords: autocatalysis, coatings, alloys, hydrogen generation, electrolytic cell

\section{INTRODUCTION}

Since the first publications [1] appeared in the field of chemical-catalytic plating with the obtaining of boroncontaining coatings, the essential progress was made both in the theoretical and applied aspect. Due to this, such coatings have been broadly used in industry. This process runs without application of external current and has the autocatalytic nature. The advantage of this plating process is a possibility to metalize the dielectrics, to obtain the uniform layers on details with complex configuration and ensure the co-deposition of boron along with the reduced metals. Boron, under the low-temperature treatment, is involved in the phase interactions with metals, forming the solid functional coatings. These coatings were proposed to be used as substitutes of precious metals in the molding of microelectronics[2,3]. Such new directions have been developed as chemical-catalytic plating with poly-metallic alloys obtaining [4,5], metallization of fine non-metal particles [6], obtaining of composite coatings [7], their applications in photo-catalysis [8].It could be expected that with the development of these processes theory and deeper studies of coatings' properties, they will be used even broader.

On the first stage of this technology development, sodium borohydride $\left(\mathrm{NaBH}_{4}\right)$ was used as a reducer. It was supposed [9], that during the hydrolytic decomposition of $\mathrm{NaBH}_{4}$ the released electron is transferred on the metal surface to the proton - electrons acceptor, resulted from water dissociation: $\mathrm{H}_{2} \mathrm{O} \leftrightarrow \mathrm{H}^{+}+\mathrm{OH}^{-}$.Hydrogen ion is transformed into hydrogen atom: $\mathrm{H}^{+}+\mathrm{e} \rightarrow \mathrm{H}$, and then the molecular hydrogen is formed: $\mathrm{H}+\mathrm{H} \rightarrow \mathrm{H}_{2}$. In the presence of nickel ions, electrons of boron-hydride ions and its hydrolysis products, as well as hydrogen atom's electrons, aregeneralized with metal surface, thus reducing nickel ions to metal, according to the general type reactions:

$$
\begin{aligned}
& \mathrm{NaBH}_{4}+4 \mathrm{NiCl}_{2}+8 \mathrm{NaOH} \rightarrow 4 \mathrm{Ni}+\mathrm{NaBO}_{2}+8 \mathrm{NaCl}+6 \mathrm{H}_{2} \mathrm{O} \\
& 2 \mathrm{NaBH}_{4}+5 \mathrm{NiCl}_{2}+8 \mathrm{NaOH} \rightarrow 2 \mathrm{~B}+5 \mathrm{Ni}+10 \mathrm{NaCl}+8 \mathrm{H}_{2} \mathrm{O} .
\end{aligned}
$$

Several more mechanisms of these processes have been proposed, including the possibility of electrochemical auto-catalytic reaction, accompanied with the anodic oxidation of $\mathrm{BH}_{4}^{-}$andcathodic reduction of $\mathrm{Ni}$. The absence of unified viewpoint may be due to the complexity of phenomena, occurring on the formation of Ni-B coatings. The most justified explanation of these processes mechanism is given in [2], based on the isotopic analysis of hydrogen composition, formed on the reactions running in heavy water, using the chemicals marked with deuterium. It is proposed that the reactions are running following the scheme:

$$
\begin{gathered}
\mathrm{BH}_{4}^{-}+4 \mathrm{OH}^{-} \rightarrow \mathrm{B}(\mathrm{OH})_{4}^{-}+4 \mathrm{H}^{+}+4 \mathrm{H}+4 \mathrm{e} \\
2 \mathrm{Ni}^{2+}+4 \mathrm{e} \rightarrow 2 \mathrm{Ni} .
\end{gathered}
$$

Boron reduction and its inclusion in composition of forming coatings occurs due to the series of other redox-catalytic processes, one of them being the intermediate formation of borine $\left(\mathrm{BH}_{3}\right)$ and its decomposition on the catalytically active metal surface: 


$$
\begin{gathered}
\mathrm{B}(\mathrm{OH})_{4}^{-}+3 \mathrm{e} \longrightarrow \mathrm{B}+4 \mathrm{OH}^{-}, \text {or }(\mathrm{V}) \\
\mathrm{BH}_{4}^{-}+\mathrm{H}^{+} \stackrel{M}{\longrightarrow} \mathrm{BH}_{3}+\mathrm{H}_{2} \longrightarrow \mathrm{B}+2,5 \mathrm{H}_{2}
\end{gathered}
$$

In the last years, the processes of nickel and its alloys chemical-catalytic reduction, using the dimethyl-borane (DMAB) $\left.\left(\mathrm{CH}_{3}\right)_{2} \mathrm{HN} \cdot \mathrm{BH}_{3}\right)$ as a reducer, which ismore stable in water solutions, are broadly used [10,11]. Therefore, a deeper study of the reactions mechanism and functional properties of coatings is needed in order to ensure the possibility of governing these processes and broaden the area of their practical applications.

\section{EXPERIMENTAL}

The coatings were deposited using $\mathrm{NaBH}_{4}$ and $\mathrm{DMAB}$ as reducing agents. To provide comparability of results while studying the effect of doping Ni-B alloys with molybdenum, tungsten or rhenium, pyrophosphate solutions with rather similar compositions were chosen. As a result of the performed optimization of main solution ingredient' concentrations, electrolytes with the following compositions(M/l) have been proposed for deposition of alloys:

1. Ni-B: $\mathrm{NiCl}_{2} \cdot 2 \mathrm{H}_{2} \mathrm{O} \ldots$. 0,26; Ethylendiamine $50 \% \ldots$. 1,$03 ; \mathrm{NaOH} \ldots .1,0 ; \mathrm{NaBH}_{4} \ldots 0,027$. $\mathrm{TlCH}_{3} \mathrm{COO}-3,7 \cdot 10^{-4}$. Temperature $-90{ }^{\circ} \mathrm{C}, \mathrm{pH}-13,5-14,0$;

2. Ni-Re-B: $\mathrm{NiSO}_{4} \cdot 7 \mathrm{H}_{2} \mathrm{O} \ldots 0,1 ; \mathrm{KReO}_{4} \ldots 0 \div 0,018 ; \mathrm{K}_{4} \mathrm{P}_{2} \mathrm{O}_{7} \ldots 0,3 ;\left(\mathrm{CH}_{3}\right)_{2} \mathrm{HN} \cdot \mathrm{BH}_{3} \ldots 0,05$;

3. Ni-Mo-B: $\mathrm{NiSO}_{4} \cdot 7 \mathrm{H}_{2} \mathrm{O} \ldots 0,1 ; \mathrm{Na}_{2} \mathrm{MoO}_{4} \ldots 0,013 ; \mathrm{K}_{4} \mathrm{P}_{2} \mathrm{O}_{7} \ldots 0,15 \div 0,3 ;\left(\mathrm{CH}_{3}\right)_{2} \mathrm{HN} \cdot \mathrm{BH}_{3} \ldots 0,06$;

4. Ni-W-B: $\mathrm{NiSO}_{4} \cdot 7 \mathrm{H}_{2} \mathrm{O} \ldots 0,1 ; \mathrm{Na}_{2} \mathrm{WO}_{4} \ldots 0 \div 0,02 ; \mathrm{K}_{4} \mathrm{P}_{2} \mathrm{O}_{7} \ldots 0,3 ;\left(\mathrm{CH}_{3}\right)_{2} \mathrm{HN} \cdot \mathrm{BH}_{3} \ldots 0,06$;

The study of structural-phase transformations of Ni-B coatings was performed using the electrohographic, Roenthgenographic and thermoderivatographic methods. To carry out electronographic research, thin $0,1-0,15 \mathrm{mkm}$ films of Ni-B coatings were deposited on the intert acetylcellulose substrate, which has been further dissolved in amylacetate. The measurements were conducted on electrohograph EG, designed and manufactured at the Crystallography Institute of Russian Academy of Sciences. As a standard, $\mathrm{NH}_{4} \mathrm{Cl}$ applied by condensation method was used.

Thermoderivatographic analysis was performed on F.Paulik, I.Paulic, L.Erdei derivatograph.The coating was heated either on air, or in vacuum under $10^{-3} \mathrm{mmmercury}$ pressure. Roentgenographic research was carried out both in the chambers РКУ-57 andРКД-114, and on difractometer УРС-50Иon $\mathrm{Cu}-\mathrm{K}_{\alpha}$ and $\mathrm{Fe}-\mathrm{K}_{\alpha}$ irradiations. Forqualitativemeasurements, microphotometerMФ-4wasused. Quantitative phases ratio, formed as a result of phase-disperse transformations on thermal treatment of boron-containing coatings, was estimated by the intensity comparison of nearby bands.It was considered thus [12], that the intensity of small crystal dispersion in the reflected state is proportional to its volume. The calculations have been performed using the working formula [13]:

$$
\frac{I_{h k l}^{m}}{I_{h k l}^{n}}=\frac{k_{1}}{k_{2}} \cdot\left(\frac{V_{2}}{V_{1}} \cdot \frac{F_{1}}{F}\right)^{2} \cdot \frac{P_{1} \cdot \rho_{2}}{P_{2} \cdot \rho_{1}},
$$

where $I$ - bands intensity; $k$ - multiplication factor for reflection; $F_{h k l}$ - structural factor for reflection; $P$ - weight; $\rho$ - density; $V$-total volume of given phase, or, expressed by weight characteristics, $V=\frac{P}{\rho}$.

The effect of potassium molybdate, sodium tungstate and potassium perhenate concentration on the basic parameters of chemical-catalytic reduction of metal ions and hydrogen was studied. The chemical state of elementsand composition of the coatings near the surface layers were studied using the method of X-ray photoelectron spectroscopy $[14,15]$. The amount of molecular hydrogen evolved was determined volumetrically and that of hydrogen adsorbed by the deposit was measured using vacuum extraction method at $400^{\circ}$ [16]. DMAB concentration in the solution was determined using the iodometric method [17].

The alloy coatings were plated on 20x10 and 25x5 mm copper and nickel plates. Information on elementary composition was obtained by local spectral analysis, using the scanning electron microscope JSM-3 with energy analyzer WINEDS. Chemical state of the elements and composition of coatings' surface layers was studied by the Roentgen photoelectron spectroscopy (RPES) $[18,19]$. At the same time, the structure, composition and chemical state of the elements in alloy was determined. To study the composition of near-surface layers of the coatings, the method of layer dissolution (alkalinization) with Ar ions was used with the energy $5 \mathrm{keV}$ and density $60-70 \mathrm{mkA} / \mathrm{cm}^{2}$. The dissolution was performed on the surface no less than $1 \mathrm{~cm}^{2}$, the analysis was done on the $0,5-0,6 \mathrm{~cm}^{2}$ middle part of the surface, 
which excluded to use for analysis the non-sprayed portions. The composition of remote layers was determined with «Talystep» profilometer and electron microscopy. Composition of layers, uncovered with the ionic dissolution, was estimated using the method of relative sensitivity factors, considering the ionic spraying coefficients.

The deep layers of deposits have been opened with diamond scribing in preparatory chamber of spectrometer (vacuum $10^{-6}-10^{-7} \mathrm{~Pa}$ ). Their composition was determined by the same method of relative sensibility factors, and compared with the data of quantitative Roentgeno-spectral analysis. All the data were obtained on spectrometer VG MkII, using the Roentgen $\mathrm{Mg} \mathrm{k}_{\alpha}$ - irradiation. The calibration of bond energy $\left(\mathrm{E}_{\text {bond }}\right.$ ) of spectral lines was performed regarding the position of bands $\mathrm{Au} 4 \mathrm{f} 7 / 2$ maximum with $\mathrm{E}_{\text {bond }}=83,8 \mathrm{eV}$ of gold film, sprayed on the coating surface in the preparatory chamber of spectrometer.

Information on chemical composition of elements in studied deposits was obtained from the analysis of form and energy position of bands maximums in the electron spectra of the ground levels Mo2d, W4d, W4f, Ni2p, O1s, B1s, C1s in the spectra of photo-electrons registered for the layers on various coatings' depths.

Nickel-rhenium-boron alloy was selected as the main model system for the study of the effect of doping element concentrations in the alloy on the kinetics of partial reactions of DMAB heterogeneous hydrolysis, reduction of hydrogen, nickel and rhenium ions. The results obtained for this alloy were compared with the specifics of partial reactions, obtained for the alloys Ni-Mo-B and Ni-W-B. It was found that the doping of nickel-boron alloys with rhenium, as well as with wolfram and molybdenum, will sharply hamperthe reaction rate of DMAB catalytic destruction (equation 2), therefore the alloys plated with the inclusions of these elements only contain the trace amounts of boron.

The effect was studied of potassium h sodium molibdate and wolframate in the solution on chemical-catalytic reduction of metal ions and hydrogen: the coatings deposition rate, electrode potential of growing alloy deposit, amount of hydrogen evolved and that of the absorbed by the coating, composition and chemical condition of elements in the alloy. The results of these studies laid in the base of the elaboration of electrode materials with low hydrogen evolving overvoltage and development of the reactor for electrochemical generation of hydrogen, using the flow-through voluminous electrodes with the improved power efficiency.

\section{RESULTS AND DISCUSSIONS}

\section{The deposition of Ni-B depositsfrom borohydride solutions.}

The specifics of the obtained Ni-B coatings' microstructure in the initial state is porous dendritic pillar nanostructure (Fig.1.). Between the dendrites there are vertical zones, which are apparently the places of hydroxide concentration and may appear due to the non-uniform distribution of boron in the deposit.

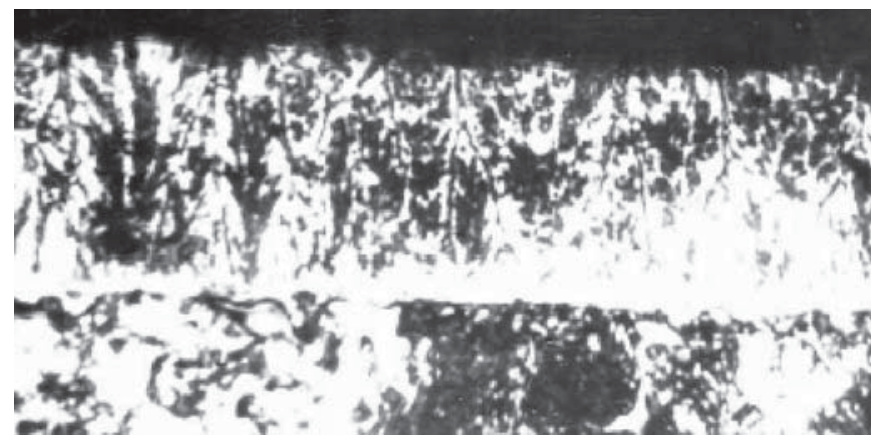

Fig. 1. Microstructure of Ni-B coatings, obtained in the presence of thallium acetate as the solution stabilizer.

On the Debye-grams only the «halo» was detected, specific for the fine or amorphous bodies. Therefore, to reveal the structure of such deposits, the research was performed with electronographic method on ЭГ type Roentgenograph at the Institute of Crystallography RAS. The specimens were prepared by plating of this films of coatings on the inert acetylcellulose substrate with subsequent dissolving in amylacetate. As the standard, $\mathrm{NH}_{4} \mathrm{Cl}$ was used, applied on the specimens by condensation method.

On the electronograms (Fig.2) of these layers of deposit (less than 0,1 mkm),8 broadened bands of nickel cubic modification are revealed, and additionally -2 very broad bands, which coincide with regard to the inter-planar distances with the strongest bands of nickel hydroxide. This phenomenon is usually observed in the case of the very fine metals [20]. 
Inter-planar distances and identification of electronogram from Ni-B deposits in the initial state

\begin{tabular}{|c|c|c|c|c|c|}
\hline Nr. & Bands intensity & hkl & $\begin{array}{c}\text { Inter-planar distance, } \\
\text { experimental }\end{array}$ & $\begin{array}{c}\text { Calculated } \\
\text { parameter of Ni }\end{array}$ & Identification \\
\hline 1. & 3 & & $2.862(2,70-$ ref.data) & & $\mathrm{Ni}(\mathrm{OH})_{2}$ \\
\hline 2. & 10 & 111 & 2,038 & 3,54 & $\mathrm{Ni}$ \\
\hline 3. & 1 & 200 & 1,771 & 3,54 & $\mathrm{Ni}$ \\
\hline 4. & 3 & 220 & 1.253 & 3,55 & $\mathrm{Ni}$ \\
\hline 5. & 3 & 311 & 1,071 & 3,55 & $\mathrm{Ni}$ \\
\hline
\end{tabular}

The average crystal size was assessed by the breadth of the first band (III)Ni $\left(1_{\mathrm{Ni}}=0,65 \mathrm{~mm}\right)$ and the nearby bands of standard $\mathrm{NH}_{4} \mathrm{Cl}\left(1_{\text {et. }}=0,30 \mathrm{~mm}\right)$, neglecting the internal stress effect, which is within the range $40-60 \mathrm{~A}$. The bond (200) is fuzzy and can hardly be observed, therefore in this direction the size does not exceed 15-20 ̃̃, the effect of packing defects is thus also possible. The signs of amorphous or crystalline boron have not been detected on electronograms, which may be explained by its low contents and low, compared to nickel, scattering power of its atoms.

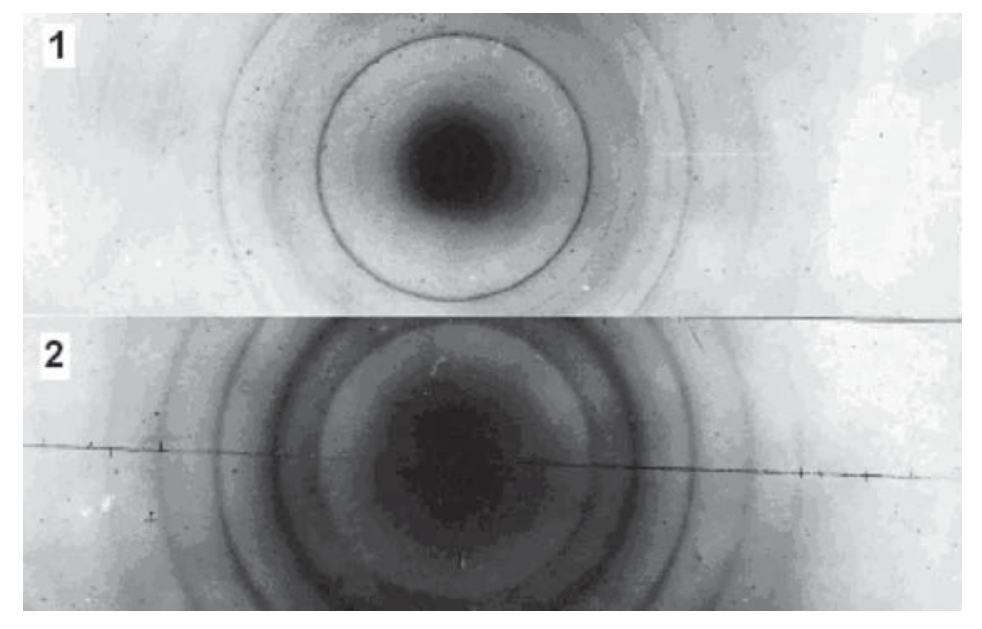

Fig. 2. Electronograms of Ni-B coatings, containing 4,3weight \% B (1) and 6,2 weight $\% \mathrm{~B}(2)$.

According to the calculation of nickel cubic lattice, its period turned out to be $\alpha=3,55 \pm 0,01 \tilde{\mathrm{A}}$, which however is

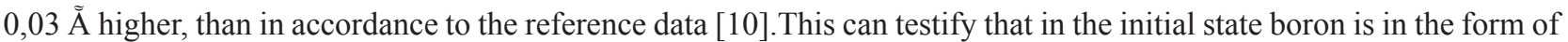
over-saturated solid solution, as the equilibrium value of boron solubility, making $0,01 \%$, should not have been reflected on the measured value of metal lattice period.

The amount of boron introduced into the coatings, depends on the factors determining the plating rateand other technological factors. As a result of heat treatment, Ni-B coatings undergo the structural-phase transformations and interact with air oxygen, therefore their properties are significantly changed. Thermoderivatographic research of the deposits made it possible to reveal the presence of two rapidly occurring irreversible exothermal effects (Fig.3). The positions of sharp peaks of the coatings with various boron contents on both derivatograms coincide. To clarify the nature of these transformations, 3-min annealing of the deposits was performed each 10 degrees within the intervals close to the transformations temperatures. 


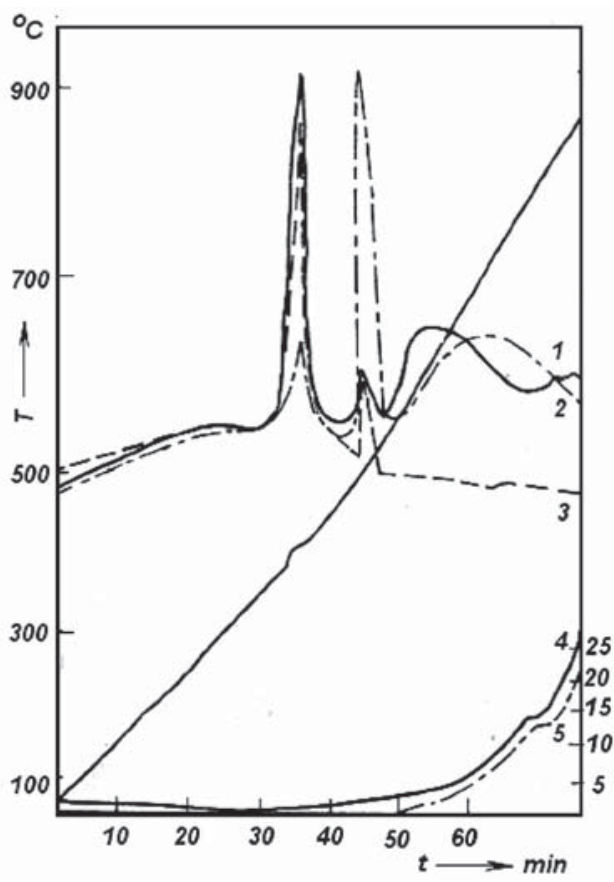

Fig. 3. ThermoderivogramsofNi-Bcoatings: 1,$2 ; 3$ DTA; 4, 5 - TG, in dependence of boron contents in the coatings;

$1,4-4,3$ weight $\% \mathrm{~B}$;

$2,5-6,2$ weight $\% \mathrm{~B}$;

$3-4,3$ weight $\% B$, annealing in vacuum.

Annealing time -3 min.

It was found that up to $310{ }^{\circ}$ Con the samples' roentgenogramsthe weak diffusion bands of cubic nickel are observed against the background of broad bands of the roentgenoamorphous phase. Under the temperature $310{ }^{\circ} \mathrm{Cand}$ higher, in the deposits containing 6,2 weight $\% \mathrm{~B}$, the clear crystalline phases appear, which have been identified as belonging to $\mathrm{Ni}_{3} \mathrm{~B}$ (main phase), $\mathrm{Ni}$ and $\mathrm{Ni}_{2} \mathrm{~B}$. When the deposits containing 4,3 weight $\%$ of boron, are annealed to 400 ${ }^{\circ} \mathrm{C}$, there are weak bands of $\mathrm{Ni}_{3} \mathrm{~B}$ phase and the intensive amorphous background. Under the higher temperatures of heat treatment, the clear lines of crystalline phases $\mathrm{Ni}_{3} \mathrm{~B}$ and $\mathrm{Ni}_{2} \mathrm{~B}$ appear, the free nickel bands thus are absent.

Comparative intensity of phase bands in dependence of heat treatment regimes

\begin{tabular}{|c|c|c|c|c|c|}
\hline \multirow{2}{*}{$\begin{array}{c}\text { Temperature, }{ }^{\circ} \mathrm{C} \text {, } \\
\text { (duration, min) }\end{array}$} & \multicolumn{5}{|c|}{ Identified phases (reflection bands) } \\
\hline & Ni (200) & $\mathrm{Ni}_{3} \mathrm{~B}(211)$ & $\mathrm{Ni}_{7} \mathrm{~B}_{3}(\mathbf{1 0 2})$ & $\mathrm{Ni}_{2} \mathrm{~B}(211)$ & $\mathrm{NiO}(200)$ \\
\hline $450(3)$ & absent & 1,8 & 5,8 & 2,4 & absent \\
\hline $500(30)$ & absent & 2,0 & 1,9 & 6,1 & absent \\
\hline $500(60)$ & absent & 5,3 & absent & 4,7 & absent \\
\hline 500 (420 vac.) & absent & 5,0 & absent & 5,0 & absent \\
\hline $700(10)$ & absent & 1,3 & 6,0 & 2,7 & absent \\
\hline $700(30)$ & 4,1 & 2,9 & absent & 3,0 & absent \\
\hline $700(120)$ & 3,4 & 1,2 & absent & 0,8 & 6,6 \\
\hline $700(240)$ & 5,6 & 1,1 & absent & 0,2 & 3,1 \\
\hline $700(420)$ & 8,6 & 1,4 & absent & absent & absent \\
\hline 700 (420 vac.) & absent & 4,0 & absent & 6,0 & absent \\
\hline
\end{tabular}

The bright bands of another phase were not possible to identify with the other well-known compounds of the system $\mathrm{Ni}-\mathrm{B}\left(\mathrm{Ni}_{4} \mathrm{~B}_{3}, \mathrm{NiB}, \mathrm{NiB}_{2}\right)$. They have been induced as belonging to the hexagonal crystal system with the parameters: $a=6,97 \pm 0,01 \AA, c=4,39 \pm 0,01 \AA$, $c / a=0,629$. The registered 30 reflections only satisfy to the following rule of reflection: $F_{h h 2 h l}=0$ when $l=2 n+1$. These are typical for the following spatial Ferorov's groups: $P 6_{3} / m m c$, $P 6_{3} / m c, P 62 c$

There are only two groups among the binary compounds, possessing the hexagonal cell, which sizes are close ( $a$

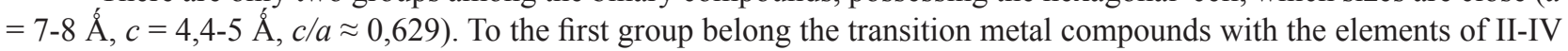


groups from the Periodic Table: structural type $\mathrm{Mn}_{5} \mathrm{Si}_{3}$, Fedorov's symmetry group $P 6_{3} / m m c$. The second group involves the borides of some transition metals, structural type $\mathrm{Th}_{7} \mathrm{Fe}_{3}$, Fedorov's symmetry group $P 6_{3} m c$. Considering that with regard to extinction, the detected compound can only belong to the second type, we have supposed that it's formula is $\mathrm{Ni}_{7} \mathrm{~B}_{3}$. This phase is thermally unstable and will be completely disintegrated within one hour under $400{ }^{\circ} \mathrm{C}$. Thus, the first exothermal peak on thermograms should be referred to the formation of $\mathrm{Ni}_{3} \mathrm{~B}$ phase, the second - mainly to the formation of $\mathrm{Ni}_{7} \mathrm{~B}_{3}$. Formation of $\mathrm{Ni}_{2} \mathrm{~B}$ phase, detected on Roentgenograms as the weak lines, also occurs under this temperature, however, this thermoeffect, apparently, is overlapping by the stronger effect of $\mathrm{Ni}_{7} \mathrm{~B}_{3}$ formation. It was found that the formation of this phase can occur under the lower temperatures, but with the longer exposition. Under $500{ }^{\circ} \mathrm{Cand}$ higher, both on the air and in vacuum, the intensity of bands $\mathrm{Ni}_{7} \mathrm{~B}_{3}$ will be sharply decreased, and at the same time the intensity of $\mathrm{Ni}_{3} \mathrm{~B}$ and especially $\mathrm{Ni}_{2} \mathrm{~B}$ bands is increasing. With further heat treatment on air, the intensity of $\mathrm{Ni}_{2} \mathrm{~B}$ lines is decreased more rapidly than that of $\mathrm{Ni}_{3} \mathrm{~B}$, the bands of nickel phases thus appear (Table 3 ). This makes it possible to suppose the reaction: $\mathrm{Ni}_{7} \mathrm{~B}_{3} \rightarrow 2 \mathrm{Ni}_{2} \mathrm{~B}+\mathrm{Ni}_{3} \mathrm{~B}$.

Crystallites size and contents in the free nickel phases under the various treatment regimes

\begin{tabular}{|c|c|c|c|}
\hline \multirow{2}{*}{$\begin{array}{l}\text { Heat treatment } \\
\text { conditions }\end{array}$} & \multicolumn{3}{|c|}{ Phases contents } \\
\hline & Crystallites size, $\mu$ & $\mathbf{I}_{\mathrm{Ni}} / \mathbf{I}_{\mathrm{Ni} 2 \mathrm{~B}}$ & Free nickel, \% \\
\hline \multicolumn{4}{|c|}{ On air } \\
\hline $250^{\circ} \mathrm{C}, 7 \mathrm{~h}$ & $2,4 \cdot 10^{-2}$ & 0,7 & 8 \\
\hline $350^{\circ} \mathrm{C}, 5 \mathrm{~min}$ & $3,5 \cdot 10^{-2}$ & 0,6 & 7 \\
\hline $350^{\circ} \mathrm{C}, 2 \mathrm{~h}$ & $4,4 \cdot 10^{-2}$ & 1,1 & 12 \\
\hline $350^{\circ} \mathrm{C}, 4 \mathrm{~h}$ & $0,2-5$ & 2,3 & 22 \\
\hline $500^{\circ} \mathrm{C}, 1 \mathrm{~min}$ & $1,5 \cdot 10^{-2}$ & 0,7 & 8 \\
\hline $500^{\circ} \mathrm{C}, 15 \mathrm{~min}$ & $0,2-5$ & 3,2 & 28 \\
\hline $500^{\circ} \mathrm{C}, 4 \mathrm{~h}$ & до80 & 5,1 & 38 \\
\hline $700^{\circ} \mathrm{C}, 1 \mathrm{~h}$ & до 80 & 19,7 & 70 \\
\hline \multicolumn{4}{|c|}{ In vacuum } \\
\hline $275^{\circ} \mathrm{C}, 7 \mathrm{~h}$ & $2,2 \cdot 10^{-2}$ & 0,7 & 8 \\
\hline $350^{\circ} \mathrm{C}, 200 \mathrm{~h}$ & $0,2-5$ & 0,6 & 7 \\
\hline $500^{\circ} \mathrm{C}, 7 \mathrm{~h}$ & $0,2-5$ & 2,5 & 23 \\
\hline $700^{\circ} \mathrm{C}, 1 \mathrm{~h}$ & $0,2-5$ & 1,8 & 18 \\
\hline
\end{tabular}

As the thermal annealing, according to the standard technology, is carried out within the longer time - up to 1 hour and more to improve the coatings with metal, this phase cannot be registered.

The data given testify on the essential phase-dispersive transformations of Ni-B coatings under the lowtemperature annealing, which may be reflected on their physical-mechanical characteristics. Therefore, the results of the research of polymetal boron-containing alloys may be of certain interest.

\section{The depositionof polymetalic alloys from dimethylamine-borane.}

The polycomponent nickel alloys with molybdenum, tungsten, rhenium and titan, obtained by autocatalytic (chemical-catalytic,electroless) reduction, have high catalytic activity[12,13]. The different complex experiments have been conducted in order to study the formation conditions and properties of these nanocatalytic systems and metal-oxide autocatalytic coatings with elevated photocatalytical activity for the destruction of high toxic organic pollutants.

The catalytic activity, chemical composition and structure of nickel-molybdenum-boron, nickel-tungsten-boron and nickel-rhenium-boron coatingswere studied. Introduction of a doping element into nickel-boron alloy changes the catalytic activity of the alloy surface as regards the concurrent partial reaction of heterogeneous hydrolysis of dimethylamine borane(DMAB) $\left(\mathrm{CH}_{3}\right)_{2} \mathrm{HN} \cdot \mathrm{BH}_{3}$, reduction of nickel ions, evolution of molecular hydrogen, boron and carbon.

The aim of this study was to elucidate the causes for nonlinear, volcano-like dependence of partial rates of DMAB hydrolysis and hydrogen evolution on the concentration of the doping element in the alloy.

The acceleration of the DMAB heterogeneous hydrolysis is explained by the change in the catalytic activity of the coating surface as the result of the subsystem restructuringduring the formation of an alloy between nickel and doping element. 
It was shown that doping of Ni-B alloys with molybdenum as well as tungsten or rhenium sharply slows down the reaction rate of $\mathrm{DMAB}$ catalytic decomposition with the reduction of boron. Therefore the boron contents in the alloys is decreased with increasing of the alloying element concentration. The deposited alloys with the inclusion of rhenium only contain the trace amounts of boron.

The mechanism of autocatalytic reduction of metal ions is based on the catalysis of the reducing agent molecules oxidation (hydrolysis), with electrons transfer to the electrode surface, which shifts its potential to the values sufficient for metal ion reduction [16-19]. For example, if DMAB is used as a reducing agent for metal ions, the electrode potential in alkali solutions is a mixed potential of the following reactions:

1. $\left(\mathrm{CH}_{3}\right)_{2} \mathrm{HN} \cdot \mathrm{BH}_{3}+3 \mathrm{D}_{2} \mathrm{O}=3 \mathrm{H}^{0}+3 \mathrm{e}+3 \mathrm{D}^{+}+\mathrm{D}_{3} \mathrm{BO}_{3}+\left(\mathrm{CH}_{3}\right)_{2} \mathrm{HN}=3 \mathrm{HD}+\mathrm{D}_{3} \mathrm{BO}_{3}+\left(\mathrm{CH}_{3}\right)_{2} \mathrm{HN}$

2. $\left(\mathrm{CH}_{3}\right)_{2} \mathrm{HN} \cdot \mathrm{BH}_{3}+\mathrm{D}_{2} \mathrm{O}=\mathrm{BH}_{3}+\left(\mathrm{CH}_{3}\right)_{2} \mathrm{HND}^{+}+\mathrm{OD}^{-}=\mathrm{B}+1,5 \mathrm{H}_{2}+\mathrm{OD}^{-}+\left(\mathrm{CH}_{3}\right)_{2} \mathrm{HND}^{+}=$ $\mathrm{B}+1,5 \mathrm{H}_{2}+\mathrm{D}_{2} \mathrm{O}+\left(\mathrm{CH}_{3}\right)_{2} \mathrm{HN}$

3. $\left(\mathrm{CH}_{3}\right)_{2} \mathrm{HN} \cdot \mathrm{BH}_{3}+3 \mathrm{D}_{2} \mathrm{O}+1,5 \mathrm{Ni}^{2+}=1,5 \mathrm{Ni}^{0}+1,5 \mathrm{H}_{2}+3 \mathrm{D}^{+}+\mathrm{D}_{3} \mathrm{BO}_{3}+\left(\mathrm{CH}_{3}\right)_{2} \mathrm{HN}$

4. $7\left(\mathrm{CH}_{3}\right)_{2} \mathrm{HN} \cdot \mathrm{BH}_{3}+12 \mathrm{D}_{2} \mathrm{O}+3 \mathrm{ReO}_{4}^{-}=3 \mathrm{Re}^{0}+10,5 \mathrm{H}_{2}+3 \mathrm{OD}^{-}+7 \mathrm{D}_{3} \mathrm{BO}_{3}+7\left(\mathrm{CH}_{3}\right)_{2} \mathrm{HN}$

5. $\mathrm{ReO}_{4}^{-}+4 \mathrm{H}_{2} \mathrm{O}+7 \mathrm{e}=\mathrm{Re}^{0}+8 \mathrm{OH}^{-}$.

("D" means hydrogen from water.)

The first two reactions characterize the possible routes of the DMAB hydrolysis. Out of these, the first reaction is the electron donor. Using mass spectroscopic studies it was shown that oxidation of hydride hydrogen in alkaline media $(\mathrm{pH} 10)$ duringheterogeneous DMAB hydrolysis proceeds to atomic hydrogen (reaction (1) ). Herewith, three electrons are generated per single dimethylamine borane molecule and molecular hydrogen $\mathrm{H}_{2}$ formed according to reactions (1) and (3) is a quantitative indicator of occurrence of the DMAB hydrolysis reaction [18].

It was established in the previous studies of the processes of autocatalytic deposition of multicomponent alloys that doping of the nickel-boron coating by molybdenum or tungsten affects significantly the rates of partial coupled reactions: DMAB hydrolysis, hydrogen evolution, and nickel deposition $[13,14,19,20]$. In the case of molybdenum, a non-monotonous dependence of the rates of partial reactions on the molybdate concentration in the solution and accordingly on molybdenum content in the alloy was found [21]: an increase in the rates of DMAB hydrolysis, nickel ion reduction and molecular hydrogen evolution was observed in the range of sodium molybdate concentrations of 0-4 mM.

Comparison of the research results on the influence of the molybdate concentration on the kinetics of the partial processes of the molecular hydrogen isolation and the deposition of the Ni-Mo-B alloys indicates on a significant role of concentration at kinetic parameters of these reactions.Increasingin $\mathrm{K}_{4} \mathrm{P}_{2} \mathrm{O}_{7}$ concentrations from 0,15 to $0,30 \mathrm{M} / 1 \mathrm{re}-$ duces the rate of partial reactions of autocatalytic process and shifts the maximum catalytic activity of the coating in the direction of higher molybdenum contents in the alloy from 6,0 to 9,0 at. $\%$.

There was a significant difference in the nature of rhenium influence on the deposition rate of nickel in comparison with molybdenum or tungsten.

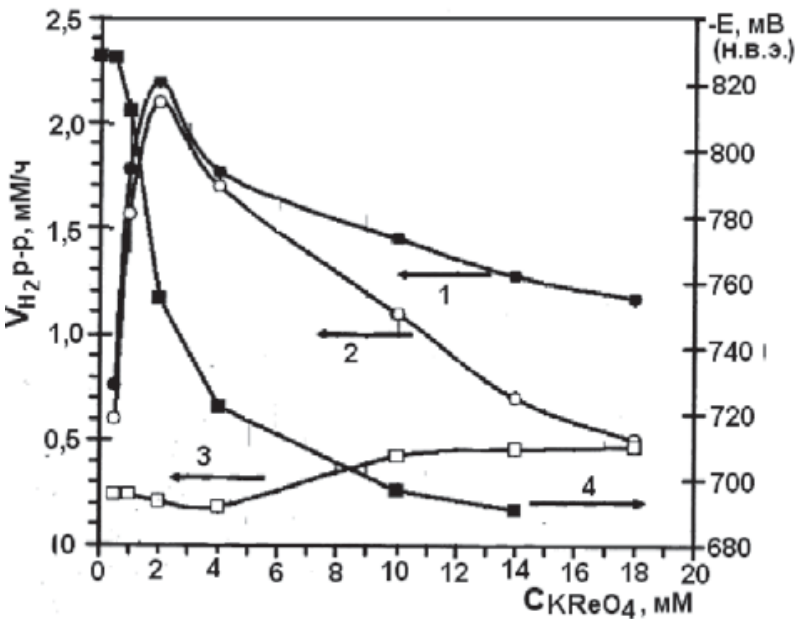

Fig. 4. Effect of potassium perhenate concentration on the kinetic parameters of plating and composition of nickel-rhenium-boron coatings: 1 - summary amount of hydrogen;

2 - hydrogen evolved as a result of DMAB hydrolysis; 3 - hydrogen evolved following the reaction 3 and 4; 4 - stationery potential of electrode.

With the increase in molybdenum or tungsten contents in the alloy, the deposition rate and rate of hydrogen evolution are changing symbatically. Doping of the same alloy with rhenium at low concentrations, accelerates the process of hydrogen evolution, but also provokes the lowerrate of nickel reduction. The observed features may be connected with the fact that molybdenum and tungsten are not allocated as a separate phase. The reduction rate of ions is determined 
by the balance of the rate of hydrolysis DMAB and nickel reduction. The rhenium is emitted in the electrochemical reduction of perhenate in a form of separate phase. Therefore with joint autocatalytic reduction of nickel and rhenium ions, there may be a possible competition of these process (reactions 3 and 5). But rhenium is not a catalyst for the hydrolysis of DMAB, and apparently direct reaction 4 is not realized.Thus, despite the differences in the mechanism of the reactions of co-deposition of molybdenum, tungsten and rhenium with nickel, the processes have common features - namely: the dependence of the rate of the alloying component on the kinetics of the reduction of nickel ions. The rate of rhenium reduction is determined by the kinetics of nickel active surface formation and therefore the composition of the alloy weakly depends on the concentration of perhenate in solution.

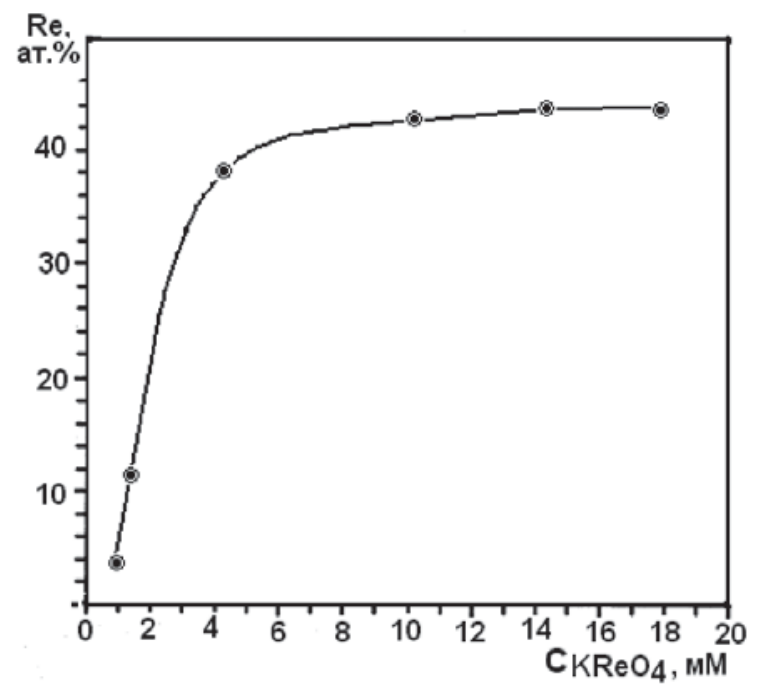

Fig. 5. Effect of perhenate concentration on rhenium contents in the nickel-boron compounds composition

The reaction of hydrogen evolution in acidic and alkaline mediums has been studied by the potentiodynamic polarization curves. Alloying of Ni-B with rhenium (11 wt.\%) reduces the overvoltage of hydrogen evolution by $200 \mathrm{mV}$.

The catalytic activity of alloys for the DMAB hydrolysis reaction has been tested in the solution without the metal ions. Maximum electrode potential for hydrolysis of DMAB is achieved with electrolytic nickel, where hydrogen overvoltage in the system is maximum, too. The lower potential is installed at the electrodes of the Ni-B alloy. For NiRe-B alloys with rhenium contents of 11 and 38 at.\%, the stationary potential is minimum. The increase of the potentialof the DMAB hydrolysis at the Ni-Mo-B alloy is slightly higher than at the Ni-Re-B alloys.

The only depolarizer in these systems is hydrogen ion (reaction 1). Therefore, stationary potential of theelectrode is determined by the balance of the DMAB hydrolysis rate and discharge of hydrogen ions. Thus, the decreasing of electrode potential with the increase of molybdenum and rheniumcontents in the alloy may be due to either a high rate of hydrogen ions discharge, or decrease in the catalytic activity of alloys in the reaction of heterogeneous DMAB hydrolysis. The overvoltage of hydrogen evolution reaction on the alloy with molybdenum or rhenium varies slightly. Therefore, the decreasing stationary potential of hydrolysis electrode is a result of the decreasing of DMAB heterogeneous hydrolysis rate. This conclusion is confirmed by the studies of DMAB hydrolysis kinetics at the electrodes with different contents of rhenium $(11,0,40,0$ and 45,0 at. $\%)$ in the solutions without the metal ions.

One reason for the lower efficiency of DMAB at the deposition of nickel-molybdenum, nickel-tungsten-boron and nickel-rhenium-boron alloys is the extremely low overvoltage of hydrogen evolution reaction. For example, the efficiency of DMAB makes $75 \%$ during the deposition of nickel-boron coatings and only reaches $17 \%$ for nickel-rhenium-boron alloy with 11 at.\% of rhenium. Although the dopingof nickel-boron alloy with other metals in low contents dramatically accelerates the hydrolysis of DMAB, the rate of polycomponent deposition is low, as the result of parasitic process of hydrogen ions discharge from water.

Examining the possible causes of the relationship changing between the rate of the partial reactions of hydrogen evolution and the rate of metal ions discharge depending on the contents of the alloying component, the different $\mathrm{pH}$ dependence of near-electrode zone of rates of reactions 3 and 5 should be taken in consideration. During the reduction of nickel (reaction 3), the acidification of the reaction zone occurs, and during the reduction of alloying component (reaction 4 or 5) - alkalization.

Since the rate of chemical-catalytic reactions considerably depends on the acidity of the medium, the reactions of nickel reduction and alloying agent reduction are conjugated and determine the partial reduction rate of nickel and molybdenum (tungsten, rhenium). Thus, during the autocatalyticreduction the self-organization occurs of thenext reactions' rate: DMAB hydrolysis, hydrogen ions discharge and metal (nickel, alloying metal) reduction. Therefore, the introduction in the plating solution of ligand-forming complexes with nickel ions, has a significant influence on the kinetics of all 
partial reactions. While discussing the possible reasons of catalytic activity of the electrode in the reactions of hydrogen evolution and the DMAB hydrolysis, the surface morphology and phase structure of alloys needs to be considered.

To estimate the effect of these factors on the partial reactions'kinetics of metal ions autocatalytic reduction, the structure of coatings and uniformity of element distribution was studied. According to the results of X-ray analysis, NiMo-B and Ni- Re-B coatings have nanocrystalline structure and Ni-W-B - amorphous structure.

The estimation of nanocrystal size by broadening reflex (111) gives value less than $20 \mathrm{~nm}$. The alloys with this minimal size of nanocrystals have maximum catalytic activity. The several-micron size somatoids, formed from smaller particles, have been found on the coating's surface. The macro-scale distribution of high elements within the volume of coating is uniform, but at the nano-scale the nanocrystals have a bulbous structure with uneven distribution of alloying element on the grain's body. The small size of crystals, a highly developed surface and heterogeneity of composition of coatings (in nano-scale) play an important role in determining of the adsorption heat, the degree of surface coverage, orientation of DMAB molecules and intermediates formed at various stages of oxidation of DMAB.The DMAB adsoption on the electrode surface not only reduces the barrier height of the successive steps ofDMAB oxidation, but,according to the results of a study of the hydrogen evolution kinetics, reduces the rate ofatomic hydrogen recombination as well.

Therefore, the introduction of molybdenum and rhenium into nickel-boron alloys change their catalytic activity in the next reactions: concurrent partial processes of DMAB heterogeneous hydrolysis, reduction of nickel ions, evolution of molecular hydrogen, elemental boron and carbon in the form of alloying metal carbide.

The observed acceleration of DMABheterogeneous hydrolysis is explained by the change in catalytic activity of coatings as the result of the subsystem restructuring during the formation of alloy between nickel and doping element.

To clarify the causes, determining the dependence of DMAB electrocatalytic hydrolysis kinetics, reduction of nickel and hydrogen ions from the concentration of alloying component (molybdate, tungstate, perhenate), the additional studies have been performed.

As soon as rhenium, in contrast to molybdenum and tungsten, do not form passive surface film of semi-product reduction of perhenate, it eliminates the effect of coating passivation during the DMAB hydrolysis. Taking into account that these alloying metals are characterized by low potential of hydrogen evolving, it can be expected that introduction of rhenium in the nickel-boron alloy can affect the rate of nickel and hydrogen ions partial reduction. The development of nickel-rhenium-boron alloys obtaining ways is also a matter of independent interest as a method of a nanocrystalline material with high catalytic activity creating.

At sodium tungstate concentrations of $300 \mathrm{mMand}$ potassium perhenate concentrations of $18 \mathrm{mM}$, the volcanolike partial rates of Ni-W-B and Ni-Re-B deposition and the molecular hydrogen release rate were revealed. The maximum deposition rate is within the range of tungstate concentrations of around $50 \mathrm{mM}$ and perhenate concentrations of around $2 \mathrm{mM}$, accordingly. At higher concentrations of potassium perhenate, the sharper decrease in partial process rate, compared to the deposition of Ni-W-B alloy, was observed. That may be due to the strong $\mathrm{pH}$ increasein the reaction zone due to the high rate of rhenium incorporation in the alloy. Thus, rhenium contents in the deposit reaches 44-54 at.\%.

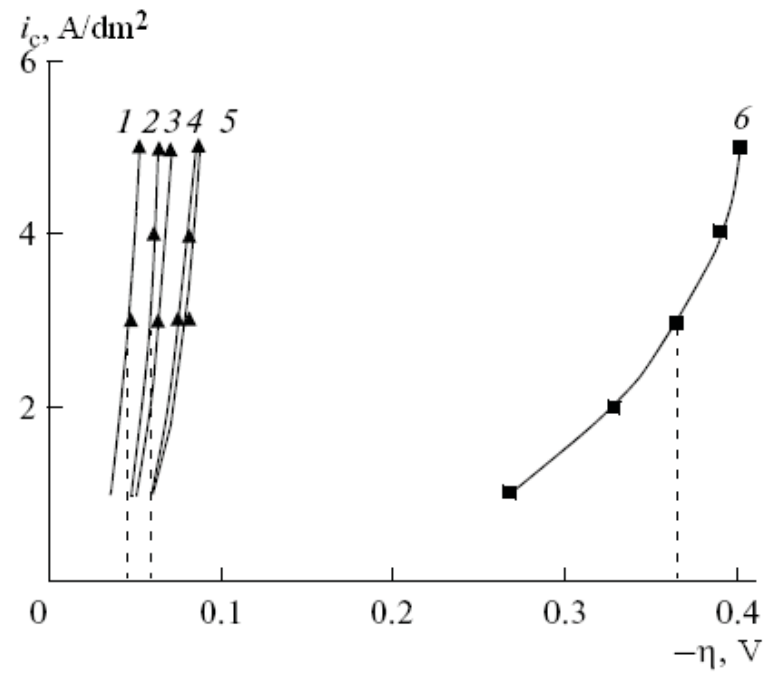

Fig. 6. Dependence of hydrogen evolving voltage from the cathode current density $i_{c}$ in $0,5 \mathrm{M} \mathrm{H}_{2} \mathrm{SO}_{4}$ solution: 1 - Pt-covered platinum(Pt); 2 - Ni-Re (4 at.\%)-B; 3 - Ni-Re (4 at.\%)-B; 4 - Ni-Re (11 at.\%)-B; 4 - Ni-Re (38 at.\%)-B; 5 - Ni-Re (45 at.\%)-B; 6 - Ni-Re (45 at.\%)-B; 6 - Ni-B. 
As follows from the data shown on Fig.6, hydrogen emission overvoltage in $0,5 \mathrm{M} \mathrm{H}_{2} \mathrm{SO}_{4}$ solution on the surface of Ni-Re-B alloys with the various contents in rhenium essentially decreases (from $-0,365$ to $-0,060-0,080 \mathrm{~V}$ under 3 $\mathrm{A} / \mathrm{dm}^{2}$ ), compared to the Ni-B coating. The lowest overvoltage of hydrogen emission is observed on the alloys with Re contents $4-11 \%$, the overvoltage values being close to ones on the Pt-coated platinum, making $-0,046$ Vunder $i_{c}=3$ $\mathrm{A} / \mathrm{dm}^{2}$. With the increase in rhenium contents in the alloy, hydrogen discharge overvoltage is increased in average by $0,020 \mathrm{~V}$. This can characterize the higher electrocatalytic properties of Ni-re coatings, that can be used, for instance, in hydrogen power engineering [21,22].

Apparently, for Ni-W-B system, the decrease of partial reaction rates after maximum is associated with the accumulation of W compounds in the reaction zone. With the increase in sodium tungstate concentration in solution, the contentsin tungsten in the alloy inreases, reaching the values of 4,0 at.\% at $200 \mathrm{mM}$.

We have also studied the theoretical bases of the processes, which lead to photocatalytic activity of some metal oxides. New method of photocatalytically active coatings obtaining, including the deposition of autocatalytic Ni-Ti-B and Ni-Re-B alloys, has been proposed. The deposition occurs on a porous ceramic base from the solution, containing nickel sulfate, titanium lactate or potassium perhenate, lactic or boric acid, thiourea, ammonium hydroxide and dimethylamineborane as reducing agent. After the coatings formation, they were anodized in the electrolyte containing titanium potassium oxalate, oxalic acid and boric acid at the current density of $0,5-1,0 \mathrm{~A} / \mathrm{dm}^{2}$, voltage $27-30 \mathrm{~V}$ and electrolysis duration of 30-60 minutes.

In this way, it was found that Ni-B coatings in the initial state represent a solid solution of boron in nickel, whereas the average size of nickel crystallites in the direction (III) is within the range of 40-60 ̊. Under the short-term annealing up to $320-350^{\circ} \mathrm{C}$, the phase $\mathrm{Ni}_{3} \mathrm{~B}$ is formed, and under the further annealing up to $410-420^{\circ} \mathrm{C}$ within the several minutes of exposure - phase - фаза $\mathrm{Ni}_{2} \mathrm{~B}$, as well as a new phase, which supposed composition is $\mathrm{Ni}_{7} \mathrm{~B}_{3}$. However, this phase is thermally unstable and is decomposed to $\mathrm{Ni}_{2} \mathrm{~B}$ and $\mathrm{Ni}_{3} \mathrm{~B}$ the faster, the higher is an annealing temperature.

\section{CONCLUSIONS}

1. It was found that the structure of chemically plated $\mathrm{Ni}$-containing coatings obtained from the boron-hydride solutions, represents in the initial state the oversaturated boron interstition solid solution into the nickel crystal lattice, with the dimensions of 40-60 ̊̃ in the direction (111), whereas in the direction (200) -no more than 15-20 А̃;

2. The nature of structural-phase transitions which occur during the thermal processing of Ni-B coatings was established; the formation of a new intermediate phase was revealed, identified as a $\mathrm{Ni}_{7} \mathrm{~B}_{3}$, which is thermally unstable, and will be decomposed forming $\mathrm{Ni}_{2} \mathrm{~B}$ and $\mathrm{Ni}_{3} \mathrm{~B}$ within one hour-time under the temperature $\geq 400{ }^{\circ} \mathrm{C}$;

3. The essential reducing of hydrogen evolving overvoltage has been found, due to the alloying of Ni-B coatings with rhenium (11 at.\%) in the solutions containing dimethylamine-borane. This effect can be used for the development of a type new reactor for the electrochemical generation of hydrogen.

\section{ACKNOWLEDGEMENT}

This research has been performed with the financial support of Russian Foundation of Fundamental Research and the Academy of Sciences of Moldova (Grant \# 08.820.08.15 "Study of the preparation and properties of nanocatalysts and composite metal-oxide chemical coatings, to be used for the photo-catalytical destruction of toxic organic pollutants").

\section{REFERENCES}

[1]. Gorbunova, K.M.; Ivanov, M.V. Application of metal coatings with the help of boron-containing reducers. Science Resume: Electrochemistry, M.: VINITI, 1977, 1970, 12, 122 p.

[2]. Petrov, Yu.N.; Covaliov, V.V.; Marcus, M.M. Proc. Acad. Sci. USSR, 1971, 198, Nr.4, pp 118-121.

[3]. Covaliova, O.V.; Covaliov, V.V. Patent Nr.2913 (MD).Method of electrochemical deposition of soldering Ni-Sn-B coatings, BOPI, 2005, 11.

[4]. Covaliova, O.V.; Ivanov M.V.; Covaliov, V.V. Patent Nr.2912(MD). Method of plating of Ni-Cu deposits. BOPI, 2005, 11.

[5]. Covaliova, O.V.; Covaliov, V.V.; Ivanov M.V.; Duca, Gh.G. Patent Nr. 3806 (MD). Method of obtaining of photocatalitically active deposits. BOPI, 2009, 1.

[6]. Covaliova, O.V.; Covaliov, V.V.; Ivanov M.V. Patent Nr.4318 (MD). Chemical deposition of boron-containing metal layers. BOPI, 2007, 10.

[7]. Covaliova, O.V.; Covaliov, V.V.; Ivanov M.V. Patent Nr.244Y (MD). Electrode for electrolytic obtaining of hydrogen and process of its manufacturing. BOPI, 2010, 7.

[8]. Covaliov, V.V.; Covaliova, O.V.; Ivanov M.V. Patent nr.3275 (MD). Device for chemical metallization of fine non-metal particles. BOPI, 2007, 3. 
[9]. Covaliova, O.V.; Covaliov, V.V.; Ivanov M.V. Patent Nr.2799(MD). Method of composite chemical coatingsdepositing. BOPI, 2005, 6.

[10]. Markin, L.I. Reference Book on Roentgen-structural analysis, M: Fizmatgiz Publ., 1961.

[11]. Kovba, L.M.; Trunov V.K. Roentgen-Phase analysis. M: MGU Publ., 1969.

[12]. Krutskich, V.M.; Ivanov, M.V.; Drovosekov, A.B.; Polukarov, Yu.M.Zaschita Met., 2005, 41, p451.

[13]. Drovosekov, A.B.; Ivanov, M.V.; Krutskich, V.M.; Lubnin, E.N.; Lyakhov, B.F. Zaschita Met., 2005,41 , p61.

[14]. A.F.Bogenshyutts, U.George, Electrochemical Alloy Coating. Methods of Analysis, Moscow: Metallurgiya, 1980, p67.

[15]. Homma, T.; Komatsu, I.; Tamaki, A.; Nakai, H.; Osaka, T. Electrochim. Acta, 2001, 47, p47.

[16]. Homma, T.; Tamaki, A.; Nakai, H.; Osaka, T. J. Electroanal. Chem., 2003, 559, p131.

[17]. Krutskich, V.M.; Ivanov, M.V.; Glazunov, M.P.; Gubin, V.V. Electrokhimiya, 1994, 30, p278.

[18]. Drovosekov, A.B.; Ivanov, M.V.; Krutskich, V.M.; Polukarov,Yu. M. Zaschita Met., 2005, 41, p4511.

[19]. Krutskich, V.M.; Ivanov, M.V.; Drovosekov, A.B., Polukarov Yu.M. Electrokhimiya, 2008, 44, p784.

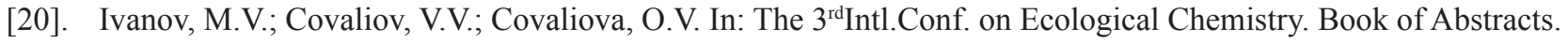
Chisinau, Moldova, 2005, pp 145-147.

[21]. Covaliova, O.V.; Covaliov, V.V.; Ivanov, M.V.; Polukarov. Yu.I. Studia Universitatis, Chisinau, 2010, 1 (31), pp 188-198.

[22]. Covaliova, O.V.; Covaliov, V.V.; Duca, Gh.; Ivanov M.V. Probl. of Reg. Power Eng., 2011, 1, p1-17. 